\title{
Pontos críticos no manejo pré-abate de frango de corte: jejum, captura, carregamento, transporte e tempo de espera no abatedouro
}

\author{
Critical points in the pre-slaughter management of broiler: feed withdrawal, \\ capture and catching, transport and lairage time in the plant
}

\author{
Bruno Rogério Rui ${ }^{{ }^{*}}$ Daniel de Souza Ramos Angrimani ${ }^{\mathrm{I}}$ \\ Marcos Augusto Alves da Silva ${ }^{I I}$
}

\section{- REVISÃO BIBLIOGRÁFICA-}

\section{RESUMO}

Atualmente, a produção avícola brasileira configura o Brasil como o terceiro maior produtor mundial de carne de frango. A cadeia avícola é um setor extremamente organizado em todos seus segmentos, do nascimento ao abate das aves. Um dos procedimentos mais laboriosos é o período pré-abate, que compreende desde o jejum até o tempo de espera no abatedouro. Devido a esse fato, este trabalho salienta os principais pontos críticos existentes no período pré-abate: o jejum, a captura, o carregamento, o transporte e tempo de espera no abatedouro.

Palavras-chave: avicultura, jejum, pontos críticos do abate.

\section{ABSTRACT}

Today the brazilian poultry industry sets Brazil as the third largest producer of chicken meat. The poultry production sector is extremely organized in all its segments, from birth to slaughter poultry. One of the most laborious is the pre-slaughter, which ranges from the feed withdrawal to the lairage time at the plant. Due to this fact this research highlights the most critical points in the pre-slaughter period, as: feed withdrawal, capture, catching, transport and lairage time in the plant.

Key words: aviculture, critical points in the pre-slaughter, feed withdrawal.

\section{INTRODUÇÃO}

OBrasil produziu, em 2009, mais 10,9 milhões de toneladas de carne de frango, configurando-se como o terceiro maior produtor mundial e o primeiro em exportação, já que 33\% de toda produção é exportada (SINDIAVIPAR, 2010). A produção nacional atinge altos níveis de desempenho em relação ao ganho de peso, conversão alimentar e baixos índices de mortalidade. Isso é reflexo de boa genética, ambiência adequada, nutrição de boa qualidade e um manejo correto desde a preparação do aviário para a chegada dos pintinhos até a retirada do lote, o chamado período pré-abate (PEREIRA, 2010).

A identificação das perdas ocorridas durante as operações pré-abate torna-se um ponto crucial na otimização dos processos de produção. Sendo que atrelar estes conhecimentos à redução de perdas é fundamental, pois se trata do acompanhamento de observações técnicas das operações do chamado segmento "pós-porteira". Visto que várias são as pesquisas direcionadas para o segmento de "dentro da porteira", pouco se sabe sobre o que realmente ocorre com as aves após deixarem as granjas (VIEIRA et al., 2009).

${ }^{\text {IC }}$ urso de Medicina Veterinária, Universidade Estadual do Norte do Paraná (UENP), Rodovia BR-369, Km 54, Vila Maria, 86360000, Bandeirantes, PR, Brasil. E-mail: brunorrui@hotmail.com. *Autor para correspondência.

"Departamento de Veterinária e Produção Animal (DVPA), UENP, Bandeirantes, PR, Brasil. 
Assim, devido à importância desse tema, nesta revisão, serão apontados os principais tópicos do manejo pré-abate de frangos de corte, sendo estes: jejum, captura, carregamento, transporte e tempo de espera no abatedouro.

\section{DESENVOLVIMENTO}

Jejum pré-abate

O jejum pré-abate inicia-se antes do carregamento das aves até o abate, e é definido como o período em que a ração é retirada, sendo fornecida a estas apenas a água (NORTHCUTT, 2000). A sua finalidade é minimizar a contaminação no abatedouro devido ao esvaziamento do sistema digestório, e melhorar a eficiência produtiva, pois não haveria tempo para que o alimento consumido fosse metabolizado e transformado em carne (MENDES, 2001).

O tempo gasto no período de jejum tem sido amplamente discutido, variando entre 8 a 12 horas, no entanto, ele é influenciado pela logística da empresa, distância até o abatedouro e o tempo de espera na plataforma, podendo assim ter sua duração prolongada (NORTHCUTT et al., 1997).

A ave normalmente se alimenta a cada 4 horas e consome água posteriormente, a fim de solubilizar a ração. Entretanto, a velocidade de passagem de alimento no intestino é influenciada pelo período de jejum, já que ele faz com que a velocidade de passagem do alimento diminua (MENDES, 2001).

A retirada da água com a ração é incorreto, pois a água auxilia na passagem do alimento no sistema digestório. $\mathrm{O}$ tempo exacerbado no jejum pode acarretar um aumento no consumo de água e ingestão de cama, isso resulta em um aumento da umidade das fezes, concluindo de maneira equivocada que o tempo de jejum foi curto. Para uma menor contaminação no abatedouro é fundamental que o intestino esteja vazio, sendo necessário que o papo também esteja vazio no momento da apanha (MENDES, 2001).

A velocidade de passagem do alimento no sistema digestório diminui com a temperatura elevada (MAY et al., 1988). Segundo MENDES (2001), aves colocadas em engradados de transporte retêm mais a ingesta do que aquelas mantidas soltas no piso e com acesso à água. Por isso, recomendaram que o tempo de transporte não seja considerado na definição do tempo de jejum.

Quando GARCIA et al. (2008) compararam os períodos de jejum de 4, 8, 13 e 17 horas, concluíram que ele é proporcional à perda de peso vivo de frangos de corte antes do abate. No entanto, não houve perda no rendimento de carcaça, cortes e nos aspectos qualitativos da carne. Observa-se que quanto maior o tempo em que as aves foram submetidas ao jejum, menor foi seu peso vivo no momento do abate, assim como o peso de carcaça quente. Entretanto, não houve diferença para o rendimento de carcaça quente entre os tratamentos testados. No peso de carcaça fria, houve diferença nos períodos de 4 e 17 horas, no entanto, encontrou-se diferença para os rendimentos de carcaça fria entre os quatro períodos de restrição de alimento.

À medida que o tempo de jejum aumenta, o peso das aves diminui (MENDES, 2001), devido à desidratação ocorrida nos músculos (DUKE et al., 1997). Segundo ROSA et al. (2002), a perda de peso varia de $0,20 \%$ a $0,40 \%$ por hora de jejum. Aproximadamente entre 50 a $75 \%$ da perda de peso vivo durante as primeiras 4 horas do jejum é devido à perda de água e matéria seca do conteúdo intestinal (DUKE et al., 1997). ASSAYAG JR et al. (2005) compararam o tempo de jejum com a perda de peso e, no trabalho, foram avaliados os períodos de jejum de uma hora a 12 horas. O estudo confirmou que, quanto maior o tempo de jejum, maior a perda de peso.

Com o aumento do tempo de jejum, as aves sofrem estresse, desestabilizando assim a sua flora intestinal, já que abre espaço para a entrada de bactérias oportunistas, auxiliando o desenvolvimento de Salmonella sp. no ceco. Os Lactobacillus sp. presentes no papo, controlam o $\mathrm{pH}$ por volta de 3,6 , impedindo a multiplicação de Salmonella $s p$, pois o $\mathrm{pH}$ ideal para desenvolvimento dela é de 6,5 a 7,5. Entretanto, com o aumento do tempo de jejum, o pH do papo aumenta, possibilitando a proliferação de Salmonella sp. Com isso, associado à ingestão de cama devido a longa privação de alimento, a carga bacteriana no papo se eleva e este pode se romper no processamento, contaminando toda a carcaça. Portanto recomenda-se que o jejum não ultrapasse mais que 12 horas (LUDTKE et al., 2008).

RAMIREZ et al. (1997) desafiaram frangos de corte com Salmonella enteritidis, sendo que, em um grupo, o jejum foi de 18 horas e, em outro, não houve jejum. Foi investigada a presença de Salmonella enteritidis no papo e ceco, sendo que o grupo que passou pelo jejum teve uma incidência maior em relação ao outro.

Com um jejum superior a 12 horas, a parede intestinal começa a se enfraquecer, com mais de 18 horas, ela pode se romper com muita facilidade (NORTHCUTT et al., 1997). O mesmo caso pode ocorrer com a vesicular biliar, que, após 14 horas de jejum, ainda contem bile, podendo se romper e contaminar a carcaça (BIGILI et al., 1997).

Os microorganismos mais comuns encontrados em carcaças cruas de frangos são: 
Salmonella sp., Campylobacter jejuni, Staphylococcus aureus, Listeria monocytogenes, Yersinia enterocolitica, Aeromonas hydrophila e Clostridium perfringens. Eles causam diminuição do tempo de prateleira, pois deterioram a carcaça e podem ser nocivos à saúde pública, já que causam intoxicações alimentares (LEITÃO, 2001).

O clima deve ser considerado, pois, em dias com temperatura muito alta, as aves diminuem ou até cessam seu consumo de ração durante a tarde, o horário de pico de calor, e, se caso o jejum for iniciado no final da tarde, o período de jejum pode ser maior que o definido anteriormente. O contrário também é válido: em períodos mais frios, as aves tendem a se alimentar mais e se movimentarem menos, retardando o processo de digestão e aumentando o risco de, durante o abate, o papo estar cheio, elevando a contaminação da carcaça (ASSAYAG JR. et al., 2005).

Outro fator a ser considerado é o bem-estar animal, por isso se pesquisa diminuir o impacto do estresse pré-abate (ASSAYAG JR. et al. 2005). O alto nível de estresse pode diminuir o tempo de rigor mortis, ou seja, a transformação do músculo em carne e isso tem como resultado uma carne com consistência mais endurecida (MENDES, 2001).

\section{Captura}

A captura de frangos de corte é uma etapa que acontece anteriormente ao transporte, período em que os frangos, quando atingem o peso de abate, são capturados por funcionários, colocados em gaiolas e só então conduzidos até o abatedouro (RIBEIRO, 2008). Entre todas as operações pré-abate, essa é a que mais gera estresse e injúrias físicas às aves, consequentemente acarretando maior prejuízo (CASTILLO \& RUIZ, 2010).

Existem dois tipos de apanha: a mecânica ou automatizada e a manual. No primeiro, é possível que duas pessoas carreguem por volta de 7200 frangos por hora, no entanto, além de seu alto valor, as modificações nas instalações dos aviários, no transporte e plataforma inviabilizam seu uso no Brasil. Por isso, a apanha manual é a forma utilizada. Nesse modo, são formadas equipes, geralmente de 12 a 14 pessoas, a baixo custo por ave. A equipe é coordenada e orientada por um líder (CONY, 2000).

Há três formas de apanha manual: a apanha pelas pernas, sendo o método que mais causa lesão na carcaça e também o menos eficiente; o método do dorso é o mais utilizado, é a forma mais fácil de introduzir as aves dentro da caixa; e o terceiro método é a captura pelo pescoço, na qual as aves são pegas três em cada mão e a grande desvantagem são os arranhões no dorso e coxas ao introduzir as aves nas caixas. Este último também pode aumentar a mortalidade no transporte, pois a apanha pelo pescoço pode provocar asfixia (CONY,2000).

Para garantir o bem-estar das aves no momento da apanha, alguns fatores devem ser respeitados. Preferencialmente, realizá-la no período noturno, devido à temperatura mais amena, e também para que as aves tenham a capacidade visual diminuída e não se agitem com a movimentação do manipulador. Além disso, comedouros e bebedouros devem ser retirados e erguidos para que não ocorra acidente com a equipe de apanha (RIBEIRO, 2008).

Preconiza-se que as aves sejam subdivididas em grupos, podendo utilizar as caixas de transporte para isso, minimizando-se a atividade, facilitando a contenção e a captura, diminuindo a incidência de lesão de pele, pois ela geralmente é provocada quando uma ave salta sobre a outra (LUDTKE et al., 2008).

É essencial produzir o mínimo de estresse possível aos frangos, pois seu aumento gera contusões e perda de peso. Devem-se formar grupos de 200 a 250 aves, podendo cercá-las com as próprias caixas de transporte, pois o correto é levar as caixas até o frango, e não o contrário (ABREU, 2004).

A UBA (2008) recomenda que aves com qualquer problema sanitário, fraturas e lesões que comprometam seu bem-estar, não devem ser transportadas, sendo necessário o sacrifício por deslocamento cervical no próprio aviário. A entidade aconselha que se evitem os métodos de apanha pelas pernas e pescoço, devido às lesões que acarretam e também pelo sofrimento que causa nos animais, contrariando, dessa forma, as leis de bem-estar animal. Outra recomendação é que as caixas sejam fechadas e deslizadas suavemente até o caminhão e, além disso, a água só deve ser retirada no início da apanha.

Em estudo, CARVALHO (2001) confrontou os métodos de captura pelos pés e pelo dorso, obtendo maiores porcentagens de lesão em coxa, peito, asa e também maior mortalidade para a apanha pelos pés. Contudo, em seu trabalho, o autor relata que a apanha pelo dorso demanda $30 \%$ mais funcionários, custando cerca $12 \%$ a mais quando comparada a pelos pés.

LEANDRO et al. (2001) compararam dois métodos de apanha, pescoço e dorso, em relação a lesões de carcaça. Foi avaliada a captura de 376 mil aves, realizada por uma equipe de 15 pessoas. Os frangos eram introduzidos em caixas de plástico, nas quais foram transportadas 12 aves por caixa (aproximadamente $27,6 \mathrm{~kg}$ ). Verificaram que aves capturadas pelo dorso tiveram significativamente menos condenação por lesão e fratura no abatedouro, quando comparado a aves submetidas à captura pelo pescoço. 
CONY (2000) realizou um estudo semelhante ao de LEANDRO et al. (2001), porém não observou diferença em relação à incidência de lesão de carcaça entre os dois métodos. No entanto, essas diferenças entre os estudos podem ser explicadas pelo nível de treinamento da equipe, além de tamanho e modelo de caixa de transporte.

No Reino Unido, apuraram-se as principais causas de morte por traumas durante a apanha, sendo que o deslocamento e a fratura de pelve atingiram mais de $76 \%$ das condenações. Isto se deu ao bater de asas quando o apanhador suspendia a ave por somente uma perna, podendo acarretar uma torção na articulação da pelve, causando deslocamento ou fratura de fêmur. Com isso, o osso é forçado para o interior da cavidade abdominal, podendo romper os sacos aéreos e promover a entrada de sangue nos pulmões. $\mathrm{Na}$ inspeção é comum observar a combinação dos sinais de sangue na cavidade oral e deslocamento da articulação da pelve (LUDTKE et al., 2008).

\section{Carregamento}

A densidade das aves por caixa deve ser ajustada de acordo com o peso das aves, condições climáticas e tamanho da caixa. Deve-se considerar que todas as aves devem ter espaço para deitar sem ocorrer amontoamento de uma ave sobre a outra. As caixas devem ser higienizadas e estar em bom estado de conservação, sendo necessário que a empresa observe o seu estado de conservação, substituindo as que estiverem danificadas, pois podem provocar lesões nas aves (UBA, 2008).

É fundamental que as caixas tenham tampas, a fim de evitar perdas por cabeças prensadas (BARBOSA FILHO, 2008). Existem dois tipos de caixas no mercado, podendo possuir portinholas corrediça e basculante. Esta última possui duas partes que se abrem para fora para que as aves possam ser colocadas nas caixas. Com esse mecanismo há menor risco de ocorrerem traumas, evitando decepamentos e morte por pescoço prensado no momento de fechar as caixas. Essas injúrias são maiores na portinhola do tipo corrediça (OLIVO, 2006).

Sabe-se que, à medida que se aumenta o número de aves por caixa, aumenta-se a mortalidade, entretanto, há uma redução do valor do frete. CARVALHO (2001) e BRANCO (2004) recomendam o peso de $22 \mathrm{~kg}$ por caixa carregada. A densidade deve variar conforme o peso das aves, o horário e a estação do ano, devendo ser menor em dias mais quentes e no período da tarde e obviamente em aves mais pesada (BARBOSA FILHO, 2008).

Para transportar as caixas até o caminhão, deve-se utilizar um sistema de cano tipo PVC, que é distribuído no aviário, distanciados $50 \mathrm{~cm}$, facilitando o deslizamento das caixas, e um sistema de esteira para levar as caixas do chão à carroceria. O empilhamento de caixas no caminhão deve variar de sete a oito, pois as duas últimas fileiras são responsáveis por $40 \%$ das hemorragias de peito. As caixas devem ser bem presas, evitando o mínimo movimento. Para que tudo isso ocorra de maneira correta, é essencial que a equipe seja treinada (RIBEIRO, 2008).

Outra medida importante é evitar que a carga fique exposta ao sol durante o carregamento, pois as primeiras aves carregadas podem sofrer estresse térmico. Uma medida preventiva é a plantação de árvores ao redor do galpão, fornecendo sombra, ou a colocação de sombrite sobre a carga do caminhão até o fim da apanha (VIEIRA et al., 2009).

O molhamento da carga é uma alternativa para diminuir a temperatura, porém algumas condições devem ser observadas, sendo que a temperatura deve estar elevada e a umidade relativa deve ser inferior a 50\%, evitando o procedimento em dias frios. O molhamento deve ser uniforme em toda a carga (VIEIRA, 2008).

O trabalho de captura de frango, além de ser fisicamente cansativo, é desagradável devido às condições dentro do aviário. As luzes ficam desligadas, obrigando a equipe a trabalhar no escuro, próximos à cama na qual o nível de poeira e amônia pode ser muito alto. Além desses fatores, há uma grande exigência em produtividade desses funcionários, podendo causarlhes problemas de coluna. Por todos esses motivos, é um trabalho de pouca motivação, já que exige o bemestar das aves durante a apanha e o manuseio (MITCHELL \& KETTLEWELL, 2003).

Deve-se avaliar a ergonomia dos trabalhadores no momento da captura e carregamento. O trabalhador deve ser encarado como prioridade, pois seu bem-estar repercute diretamente sobre o bem-estar das aves e a qualidade final da carcaça (VIEIRA et al., 2009).

\section{Transporte}

O transporte consiste na tarefa de encaminhar as aves do aviário até o abatedouro, podendo ser executada em diferentes condições, distância e tipos de vias (BARBOSA FILHO, 2008).

Alguns estímulos podem estressar os frangos, comprometendo o bem-estar e a qualidade da carne. Os fatores estressantes são: estresse térmico devido à elevada temperatura e umidade, estresse pelo frio devido à alta velocidade do veículo de transporte e umidade, estresse social, decorrente da alta lotação nas caixas, vibração, aceleração, barulho (JORGE, 2008).

Durante o transporte, as aves são submetidas à ação direta da radiação solar, fator 
agravado durante o verão. Unido a isso, ocorre a insuficiente ventilação da carga, gerando o acúmulo de calor na ave, resultando em um maior desconforto térmico dos animais. Para dissipar o calor, muitos frangos tentam expor uma maior área do corpo e buscam ofegar, na tentativa de perder calor por evaporação. No entanto, com densidade alta por caixa, ambos os mecanismos têm sua eficácia diminuída. Portanto, quanto maior a densidade das caixas, menor será a perda de calor sensível, sendo que as aves que se encontram nas extremidades da carga sofrem menos (WARRIS et al., 2005).

A disponibilidade de oxigênio é um fator importante, pois seu baixo nível pode causar asfixia nas aves, sendo preciso que ocorra uma separação entre as fileiras de caixas que devem estar limpas, porque o acúmulo de fezes e penas atrapalha a circulação do ar. No caminhão, as caixas devem estar bem presas, evitando que se movimentem e que se soltem. O sistema mais utilizado nos veículos é o de cano nas laterais e cobertura na parte superior da carroceria. Os motoristas são parte vital no processo, eles precisam ser bem orientados e treinados, conhecendo os riscos que pode sofrer a carga que estão transportando (ABREU \& AVILA, 2003).

O planejamento antecipado do tempo de viagem é vital para poder adequar a distância do aviário até o abatedouro com as condições climáticas. Longas distâncias não podem ser associadas com períodos mais quentes do dia, pois as aves seriam submetidas a um calor excessivo por mais tempo. As chuvas também devem ser consideradas, pois estradas que não são pavimentadas podem ficar intransitáveis (VIEIRA et al., 2009).

COSTA et al. (2007) compararam a distância (aviário-abatedouro) e a posição das caixas na carga em relação ao número de aves lesionadas em duas integradoras. Nas distâncias maiores, o percentual de lesão foi mais elevado, contudo tanto em distâncias menores quanto maiores ocorreu uma maior incidência de lesão nas aves localizadas na parte traseira do veículo. Isso pode ser explicado pelos maiores efeitos de aceleração e vibração sofridos pelos animais situados neste local.

Segundo BARBOSA FILHO (2008), a morte na chegada do abatedouro, também chamada de - death on arrivals - (DOA's), pode ser ocasionada pela saúde dos animais, estresse térmico e pelos traumas sofridos no transporte nas etapas anteriores.

JORGE (2008) avaliou a taxa de mortalidade na chegada ao abatedouro e as principais lesões encontradas em três grupos: frangos de corte, galinhas de postura de descarte, matrizes de descarte. A taxa de mortalidade foi maior em animais que viajaram por períodos mais longos. Essa percentagem, 1,23\%, foi muito maior que a recomendada por BRANCO (2004) que varia $0,30 \%$ e $0,20 \%$ no verão e inverno, respectivamente. As áreas corpóreas com maiores índices de lesão foram peito e asa.

Para analisar os efeitos de altas temperaturas e umidade no transporte, SILVA et al. (2007) simularam o ambiente de transporte colocando 30 aves, 10 por caixa, em câmara climática com temperatura de $35^{\circ} \mathrm{Ce}$ umidade relativa de $85 \%$. Realizaram o teste em quatro períodos $0,30,60,90$ e 120 minutos e depois compararam a perda de peso e a temperatura, essa aferida por meio da cloaca, e frequência respiratória, esta última aferida por observação visual. A temperatura limite mínima na qual as aves começam a sofrer estresse térmico foi de $41,1^{\circ} \mathrm{C}$, já a máxima, no experimento, foi de $46,3^{\circ} \mathrm{C}$, pois o animal veio a óbito quando chegou a essa temperatura. Com relação à frequência respiratória, só foi possível aferi-la nos grupos 0, 30 e 60 minutos de exposição, pois nos outros dois grupos (90 e 120 minutos), devido a alta frequência respiratória na tentativa de eliminação do calor através da ofegação, foi impossível a contagem.

As aves apresentaram perda de peso significativa e diminuição dos pesos de pernas, asas e dorso, conforme aumentou o período de estresse térmico. O peso de peito e de vísceras não foram afetados pelo período de estresse. Esse fato deve-se à maior perda de água das extremidades do corpo (pernas e asas) no início da exposição à condição de alta temperatura e umidade. A partir de 30 minutos na exposição de $35^{\circ} \mathrm{C}$ de temperatura e $85 \%$ de umidade, as aves apresentaram evidência de estresse térmico, comprovado pela influência negativa nos parâmetros fisiológicos (temperatura e frequência respiratória) e na qualidade da carcaça, com perda de peso de pernas, asas e dorso (SILVA et al., 2007).

O estresse térmico muitas vezes é apenas associado às altas temperaturas, no entanto, as baixas também devem ser consideradas. Com o aumento da velocidade do veículo de transporte, eleva-se a ventilação e, consequentemente, as aves sentirão mais frio. $\mathrm{O}$ estresse pelo frio é agravado quando as aves estão molhadas, pois há perda de temperatura pela evaporação da água, por isso em dias chuvosos recomenda-se colocar uma proteção na parte superior da carga, e em temperaturas baixas não molhar as aves (RIBEIRO, 2008).

Tempo de espera no abatedouro

O tempo de espera é definido como o período da chegada das aves no abatedouro até o seu abate. Chegando ao frigorífico, o veículo de transporte deve ser levado ao galpão de espera e é fundamental que 
seja equipado com nebulizadores, ventiladores e que evite que a carga receba a radiação solar. No entanto, as aves podem ser abatidas logo que chegam ao abatedouro, anulando o tempo espera no galpão, porque a carga é logo descarregada na plataforma de abate (GONÇALVES, 2008).

O tempo de espera não deve ser superior a duas horas, porém, nem sempre as integradoras conseguem cumprir esse tempo, devido ao excesso de caminhões na espera para o abate e, em decorrência de quebras nos equipamentos do frigorífico. Neste caso, sendo necessário muitas vezes parar a linha de abate para realizar a manutenção (BRANCO, 2004).

No galpão de espera, as linhas de nebulizadores devem ser alternadas com as linhas de ventilação. As primeiras devem ser distribuídas uniformemente entre os pilares e o teto, a fim de que se consiga climatizar todas as caixas. $\mathrm{O}$ reservatório de água deve estar instalado na sombra. É fundamental que seja instalado nas laterais e no centro do galpão um termohigrômetro para a aferição da temperatura e umidade (VIEIRA et al., 2009).

BRESSAM \& BERAQUET (2002) e BARBOSA FILHO (2008) citam que a duração menor no tempo de espera aumenta o estresse nas aves, e consequentemente eleva a mortalidade. No entanto, WARRIS et al. (1999) afirmam o oposto, que um período de espera mais prolongado reflete em um maior estresse, indicando que as aves sejam abatidas logo que chegam ao abatedouro, contudo, deve ser feita uma análise cuidadosa, observando se os galpões têm ou não uma boa climatização, evitando deficiência na ventilação (VIEIRA et al., 2009).

Kannan et al. (1997), apud CASTILLO \& RUIZ (2010), observou que frangos abatidos após o transporte de três horas apresentaram maior nível de corticosterona comparado aos que aguardaram quatro horas no galpão de espera. O elevado nível plasmático de corticosterona resultou em uma carne mais pálida, sendo que esta tem baixa aceitabilidade pelos consumidores.

HILDEBRAND et al. (2006) analisaram o tempo de espera de 13 mil caminhões nas quatro diferentes estações do ano, observando a percentagem de mortalidade. Ela foi menor em períodos maiores de espera e nas estações de verão e primavera. $\mathrm{O}$ autor conclui que, a partir de 1 hora de espera, há uma redução no índice de mortalidade, devido à eficiência na climatização dos galpões de espera.

É de suma importância que a área de desembarque seja coberta e que as caixas sejam descarregadas com cuidado, evitando movimentos bruscos e devendo ser colocadas na esteira individualmente, evitando estresse e lesões nas aves. As caixas devem ser abertas no momento da pendura, procurando evitar que as aves fujam e, caso isso ocorra, elas devem ser capturadas e penduras na nória imediatamente. As aves que chegarem mortas devem ser retiradas das caixas e contadas, sendo lavadas juntamente com o caminhão após o termino do desembarque (GONÇALVES, 2008).

\section{CONCLUSÃO}

As operações pré-abate causam muitos prejuízos para as indústrias avícolas, entretanto, há pouca preocupação com o processo, não sendo tomadas as medidas preventivas. Além de um conforto para os animais, também deve-se pensar nos funcionários envolvidos no processo. Respeitando todas as orientações descritas, haverá certamente uma melhor qualidade no produto final que chega ao consumidor e consequentemente uma maior lucratividade para as empresas.

\section{REFERÊNCIAS}

ABREU, V.M.N. A ventilação dos aviários garante aumento na produção. Concordia, SC: Embrapa Suínos e Aves, 2004. Disponível em: <http//www.nordesterural.com.br/nordesterural/ matler.asp?newsId=870>. Acesso em: 14 abr. 2010 .

ABREU, V.M.N.; AVILA, V.S. Preparação do aviário e apanha. Concordia, SC: Embrapa Suínos e Aves, 2003. Disponível em: <http//sistemasdeproducao.cnptia.embrapa.br/ FontesHTML/Ave/ProducaodeFrangodeCorte/Manejoproducao.html>. Acesso em: 29 jun. 2010.

ASSAYAG JR., S.M. et al. Efeito da duração do jejum pré-abate sobre peso corporal de frangos de corte aos 45 dias de idade. Brazilian Journal of Veterinary Research and Animal Science, v.42, n.3, p.188-192, 2005.

BARBOSA FILHO, J.A.D. Caracterização quantiqualitativa das condições bioclimáticas e produtivas nas operações pré-abate de frangos de corte. 2008. 175f. Tese (Doutorado em Física do Ambiente Agrícola) - Escola Superior de Agricultura "Luiz de Queiroz", Universidade de São Paulo, SP. Disponível em: <http://www.teses.usp.br/teses/disponiveis/11/11131/tde17072008-153053/>. Acesso em: 11 maio, 2010.

BRANCO, J.A.D. Manejo pré-abate e perdas decorrentes do processamento de frango de corte. In: CONFERÊNCIA APINCO DE CIÊNCIA E TECNOLOGIA AVÍCOLAS, 2004, Santos, SP. Anais... Campinas: FACTA, 2004. V.2, p.129-142.

BRESSAN, M.C.; BERAQUET, N.J. Efeito de fatores préabate sobre a qualidade da carne de peito de frango. Ciência Agrotécnica, v.26, n.5, p.1049-1059, 2002.

BIGILI, S.F.; HESS, J.B. Tensile strenght of broiler intestines as influenced by age and feed withdrawal. Journal of Applied Poultry Research, v.6, p.279-283, 1997.

CARVALHO, M.F.A. Manejo final e retirada. In: CONFERÊNCIA APINCO DE CIÊNCIA E TECNOLOGIA AVÍCOLAS, 2001, Campinas, SP. Anais... Campinas: FACTA, 2001. p.59-68. 
CASTILLO, C.J.C.; RUIZ, N.J. Manejo pré-abate, operações de abate e qualidade de carne de aves. In: CONFERÊNCIA APINCO DE CIÊNCIA E TECNOLOGIA AVÍCOLAS, 2010, Santos SP. Anais... São Paulo: FACTA 2010. p.171-190.

CONY, V.A. Manejo do carregamento, abate e processamento: como evitar perdas? In: CONFERÊNCIA APINCO DE CIÊNCIA E TECNOLOGIA AVÍCOLAS, 2000, Campinas SP. Anais... Campinas: FACTA, 2000. p.203-212.

COSTA, F.M. et al. Influência das condições de pré-abate na incidência de contusões em frango de corte. Revista Veterinária e Zootecnia. v.14, n.2, p.234-245, 2007.

DUKE, G.E. et al. Optimum duration of feed and water removal prior to processing in order to reduce the potential for fecal contamination in turkeys. Poultry Science, v.76, p 516$522,1997$.

GARCIA, G.R. et al. Jejum alimentar pré-abate no rendimento e qualidadede carcaça de frangos de corte tipo griller. Agrarian, v. 1, n.2, p.2-8, 2008

GONÇALVES, R.C. Fluxograma de abate de aves. 2008. 59f. Monografia (Especialização em Higiene e Inspeção de Produtos de Origem Animal) - Instituto Quallitas, Goiânia, GO. Disponível em: <http://www.qualittas.com.br/documentos/ Flux ograma $\% 20$ de $\% 20$ Abate $\% 20$ de $\% 20$ Aves $\% 20$ $\% 20$ Cintia\%20Rodrigues\%20Goncalves.PDF>. Acesso em: 13 abr. 2010 .

HILDEBRAND, A. et al. Perdas produtivas nas operações préabate de frango de corte em relação ao tempo de espera em abatedouros: efeito das estações do ano. Núcleo de pesquisas em ambiência. Piracicaba: Escola Superior de Agricultura "Luiz de Queiroz", Universidade de São Paulo, 2006. p.1.

JORGE, S.P. Avaliação do bem-estar animal durante o préabate e abate e condição sanitária de diferentes segmentos avícolas. 2008. 107f. Tese (Doutorado em Medicina Veterinária) - Universidade Estadual Júlio de Mesquita Filho, Jaboticabal, SP. <Disponível em: http://www.fcav.unesp.br/ download/pgtrabs/mvp/d/401.pdf $>$. Acesso em: 11 maio, 2010.

KANNAN, G. et al. Effetcs of crating and transport on stress and meat quality characteristics in broilers. Poutry Science, v.76, p.523-529, 1997.

LEANDRO, N.S.M. et al. Efeito do tipo de captura dos frangos de corte sobre a qualidade da carcaça. Ciência Animal Brasileira, v.2, n.2, p.97-100, 2001.

LEITÃO, M.F.F. Qualidade e segurança alimentar em produtos avícolas. In: CONFERÊNCIA APINCO DE CIÊNCIA E TECNOLOGIA AVÍCOLAS, 2001, Campinas, SP. Anais... Campinas: FACTA, 2001. p.181-190.

LUDTKE, C.B. et al. Principais problemas e soluções durante o manejo pré-abate das aves. In: CONFERÊNCIA APINCO DE CIÊNCIA E TECNOLOGIA AVÍCOLAS, 2008, Santos. SP. Anais... São Paulo: FACTA, 2008. p.109-128.

MAY, J.D. et al. Effect of environmental temperature and feed regimen on quantity of digestive tract contents of broilers. Poultry Science, v.67, p.64-71, 1988.

MENDES, A.A. Jejum pré-abate em frangos de corte. Revista Brasileira de Ciência Avícola, v.3, p.199-209, 2001.

MITCHELl, M.A.; KETTLEWELL, P.J. Sistemas de transporte e bem-estar de frangos de corte. In: CONFERÊNCIA
APINCO DE CIÊNCIA E TECNOLOGIA AVÍCOLAS, 2003, Campinas, SP. Anais... Campinas: FACTA, 2003. p.199-215.

NORTHCUTT, J.K. Factors influencing optimal feed withdrawal duration. Tifton, the University of Georgia. College of Agricultural and Environmental Sciences, bulletin 1187, may 2000. Disponível em: <http://pubs.caes.uga.edu/caespubs/ pubcd/B1187.html>. Acesso em: 14 abr. 2010.

NORTHCUTT, J.K. et al. Relationship between feed withdrawal and viscera condition of broilers. Poultry Science, v.76, p.410-414, 1997.

OLIVO, R. O mundo do frango: a cadeia produtiva da carne de frango. Criciúma: Varela, 2006. 680p.

PEREIRA, P.E.R. Bem-estar, qualidade de carne de peito e integridade intestinal de frangos de corte. 2010. 62f Dissertação (Mestrado em Zootecnia,) - Universidade Estadual Júlio de Mesquita, Botucatu, SP. Disponível em: <http:// www.dominiopublico.gov.br/download/texto/cp120007.pdf.> Acesso em: 17 maio, 2010.

RAMIREZ, G.A. et al. Effect of feed withdrawal on the incidence of Salmonella in the crops and ceca of market age broiler chickens. Poultry Science, v.76, p.654-656, 1997.

RIBEIRO, C.S. Bem-animal como pré-requisito de qualidade na produção de frangos de corte. 2008. $47 \mathrm{f}$. Monografia (Especialização em Higiene e Inspeção de Produtos de Origem Animal) - Universidade Castelo Branco, RJ. Disponível em: <http://www.qualittas.com.br/artigos/ artigo.php?artigo_id=538>. Acesso em: 29 abr. 2010.

ROSA, P.S. et al. Efeito da temperatura e duração de jejum préabate sobre indicadores de estresse em frangos de corte abatidos aos 35 e 49 dias de idade. Avisite, 2002. Disponível em: $\langle$ http://www.avisite.com.br/cet/trabalhos.asp? codigo=37>. Acesso em: 14 jun. 2010.

SINDIAVIPAR. Disponível em: <http://www.sindiavipar.com.br/ index.php? modulo $=8 \&$ acao $=$ frango $>$. Acesso em: 29 jun. 2010 .

SILVA, N.A.M. et al. Avaliação do estresse térmico em condição simulada de transporte de frangos de corte. Revista Brasileira de Zootecnia, v.36, n.4, p.1126-1130, 2007.

UNIÃO BRASILEIRA DE AVICULTURA. Protocolo de bemestar para frangos e perus. São Paulo, jun. 2008. Disponível em: 〈http//www.uba.org.br>. Acesso em: 15 jun. 2010.

VIEIRA, F.M.C. et al. Perdas nas operações pré-abate: Ênfase em espera. Comunicado técnico, maio 2009. Disponível em: <http://pt.engormix.com/MA-avicultura/industria-carne/ artigos/perdas-nas-operacoes-preabate_152.htm>. Acesso em: 15 abr. 2010

VIEIRA, F.M.C.v Avaliação das perdas e dos fatores bioclimáticos atuantes na condição de espera pré-abate de frangos de corte. 2008. 176f. Dissertação (Mestrado em Física do Ambiente Agrícola) - Escola Superior de Agricultura "Luiz de Queiroz", Universidade de São Paulo, Piracicaba, SP. Disponível em: <http://www.dominiopublico.gov.br/download/ texto/cp060235.pdf>. Acesso em: 25 maio, 2010.

WARRIS, P.D. et al. Relationship between maximum daily temperature and mortality of broiler chickens. British Poultry Science, v.46, p.647-651, 2005

WARRISS, P.D. et al. Effects of lairage time on body temperature and glycogen reserves of broiler chickens held in transport modules. Veterinary Record, v.145, p.218-212, 1999. 